\title{
RELIABILITY STUDY OF KOLO CREEK GAS TURBINE POWER STATION
}

\author{
Y. P. Olisa ${ }^{1, *}$ and A. E. Amos ${ }^{2}$

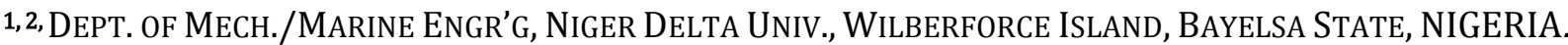 \\ Email addresses: ${ }^{1}$ yemi.olisa@yahoo.com, ${ }^{2}$ amosangelyna@gmail.com
}

\begin{abstract}
Equipment failures such as unbalanced rotating elements, steam-induced vibration, misalignment of turbine shaft and rotor malfunction create production, safety, operational and environmental problems in a thermal power plant. This paper assessed the reliability and availability status of Kolo Creek Gas Turbine Power Station. The method of reliability evaluation was based on the collection of historical operational failure database of two turbines with total installed capacity of 20 MW over a period of seven years (1995 - 2001) and the analysis of the data was carried out by applying the reliability indices model. The result of the analysis indicated reliability and availability values of $10 \%$ and 70.5\% respectively over the period under consideration. These values are very low due to too frequent failures and downtimes arising from lack of maintenance culture. It is necessary to improve the reliability indices of the power plant by employing well planned and routine maintenance of equipment as well as training and retraining of technical human resources of the major equipment.
\end{abstract}

Keywords: Failure, Downtime, Maintenance, Reliability, Availability, Indices.

\section{INTRODUCTION}

Power generation system is an important aspect of electricity supply chain and it is crucial that enough electricity is generated at every moment to meet demand. Generating units will occasionally fail to operate most especially the turbine unit Barabady [2]. Gas turbine generator set is a key device of the gas power plant, it transforms the thermal energy generated by fuel combustion into mechanical energy that rotate the electrical generator's shaft. In case of a gas turbine failure the power plant is fully shut down since the power cycle is dependent on the gas turbine availability. Bearing in mind the great importance of the gas turbine for plant operation, its availability should be carefully evaluated in order to anticipate the performance (technical and economical) of the plant Fernando [3]. The Kolo Creek Gas Turbine Station is situated at Imiringi, Ogbia Local Government Area, Bayelsa State, it was established in 1995 with a total installed capacity of 20 MW.

Reliability assessment is a comprehensive evaluation of a plant's rotating equipment to identify potential issues that may be contributing to low mean time between repair (MTBR), loss of containment, unsafe working conditions or production issues Gupta [4]. It provides a comprehensive understanding of equipment and system performance by gathering essential sensor data to evaluate where the equipment is operating compared to the design point; review preventative maintenance/predictive maintenance programs and compare to industry best practices; provide a final report to include issues identified, performance results, and recommended solutions to address areas for improvement Valdma [8]. The reliability of power plant is related to the possibility of giving electricity efficiently and more economical with a reasonable quality assurance of continuity, Wang [9].

A unique approach was developed by Phaneedra [7] for reliability modeling analysis of a mechatronic system, which is useful in visual analysis of reliability interactions among the mechatronic subsystems, Information stored in a graph is quantified and exported to a reliability variable permanent matrix and finally to a function named Mechatronic Variable Permanent Reliability Function (MVPRF). Anirban [1] applied a methodology to calculate probabilities of failure using Probabilistic Support Vector Machines (PSVMs). This has recently gained attention for reliability assessment because of several inherent advantages. Specifically, SVMs allow one to construct explicitly the boundary of a failure domain. In addition, they provide a technical solution for problems with discontinuities, binary responses, and multiple failure modes. An analysis was carried out by Monika [6] using 
the supplementary variable technique and Laplace transformation for evaluating the reliability measurement of a system having four components arranged in series. A method was proposed by Manwinder [5] to improve the scheduled preventive maintenance of a system by assessing different kinds of availability and illustrated how the corrective maintenance data can be helpful to reschedule preventively maintained system. This method uses the concept of inherent availability to ensure to what extent maximum availability can be extended.

The aim of this work was to carry out a reliability study of the Kolo Creek Gas Turbine Power Station in order to ensure proper preventive and predictive (PM/PDM) practices are in place and plant equipment availability is improved which in turn leads to increased productivity and profit.

\section{METHODOLOGY}

\subsection{Data Collection}

The data (on the failure history of the gas turbine) for the reliability evaluation of the Kolo Creek gas turbine power station was collected from the operations and maintenance department of the station and analyzed using the reliability indices.

The reliability evaluation was calculated considering a seven year operational database from 1995 - 2001. Information from the data includes: Total hours run, Capability of the units, Time of failure, Causes of failure and Mode of failure. The plant performance and operations are represented in Table 1 and 2, while Table 3 presents the total number of hours run/outages.

Table 1: Plant Performance (1995 - 2001)

\begin{tabular}{ccccccl}
\hline S/N & Unit & $\begin{array}{c}\text { Date of } \\
\text { Problem }\end{array}$ & $\begin{array}{c}\text { Time } \\
\text { (Hour) }\end{array}$ & $\begin{array}{c}\text { T.P.G } \\
\text { (MW) }\end{array}$ & $\begin{array}{c}\text { T.P.C } \\
\text { (MW) }\end{array}$ & Causes of Failure \\
\hline 1 & 1 & $24 / 06 / 95$ & $14: 00$ & 20 & $1.3-1.9$ & Tripped due to earth fault by feeder C \\
2 & 2 & $26 / 08 / 95$ & $22: 38$ & 20 & $1.5-1.7$ & Tripped on fuel control system failure \\
3 & 2 & $20 / 11 / 95$ & $02: 40$ & 20 & $1.5-1.9$ & Tripped on PT/AC gen. bearing high temp. \\
4 & 2 & $17 / 02 / 96$ & $20: 08$ & 20 & $1.5-7.0$ & Tripped on low gas pressure \\
5 & 2 & $27 / 11 / 96$ & $18: 00$ & 20 & $1.5-7.0$ & Shut down for maintenance \\
6 & 2 & $30 / 01 / 97$ & $05: 55$ & 20 & $1.9-2.6$ & Tripped on low gas pressure and shut down for \\
7 & 2 & $19 / 05 / 97$ & $07: 00$ & 20 & $1.9-2.6$ & Shut work \\
8 & 2 & $06 / 02 / 98$ & $13: 35$ & 20 & $2.0-2.7$ & Tripped on low gas pressure \\
9 & 2 & $16 / 07 / 98$ & $08: 20$ & 20 & $2.0-2.7$ & Low gas supply from shell, AC lub. Oil pump faulty, \\
& & & & & & fuel control system faulty \\
10 & 2 & $14 / 02 / 99$ & $24: 25$ & 20 & $3.0-3.5$ & $\begin{array}{l}\text { Tripped on earth fault, sudden drop on the } \\
\text { frequency from 50Hz to zero }\end{array}$ \\
11 & 2 & $25 / 03 / 99$ & $04: 20$ & 20 & $3.0-3.5$ & High vibration in system due to bearing failure \\
12 & 1 & $19 / 06 / 2000$ & $23: 40$ & 20 & $5.0-6.6$ & $\begin{array}{l}\text { High pressure of gas supply ad drop in frequency } \\
\text { due to feeder C }\end{array}$ \\
& & & & & & Tripped on closing feeder C and consequent flame \\
13 & 1 & $16 / 11 / 2000$ & $18: 47$ & 20 & $6.5-9.0$ & out due to abortive start \\
& & & & & & Tripped on thrust bearing due to high \\
14 & 1 & $02 / 03 / 01$ & $19: 50$ & 20 & $9.0-11$ & temperature \\
15 & 1 & $21 / 03 / 01$ & $14: 00$ & 20 & $9.0-11$ & Shut down due to excess smoke from the exhaust \\
16 & 1 & $11 / 10 / 01$ & $14: 21$ & 20 & 11.0 & Tripped on excessive current due to feeder A \\
\hline
\end{tabular}

T.P.G. Total Power Generated; T.P.C. $\quad$ Total Power Consumed; M.W. Megawatt

Table 2: Plant operation (1995 - 2001)

\begin{tabular}{ccccccccc}
\hline S/N & Unit & D.C. & $\begin{array}{c}\text { H.R.B.O. } \\
\text { (hours) }\end{array}$ & $\begin{array}{c}\text { H.R.A.O. } \\
\text { (hours) }\end{array}$ & A.N.O. & R.N.O. & D.F.O. & T.N.H.R. \\
\hline 1 & 1 & $26 / 04 / 88$ & $33,640.0$ & 4016.24 & 2 & 2 & $04 / 11 / 93 ;$ & $37,656.24$ \\
2 & 2 & $26 / 04 / 88$ & $38,711.7$ & - & 1 & 2 & $16 / 04 / 2000$ & $38,711.7$ \\
\hline
\end{tabular}

D.C. Date of Commissioning;

H.R.B.O. Hours run before overhaul;

H.R.A.O. Hours run after overhaul

A.N.O. Actual number of overhaul;

R.N.O. Required number of overhaul;

D.F.O. Date of first/last overhaul

T.N.H.R. Total number of hours run 
Table 3: Total hours run/outages

\begin{tabular}{llllllll}
\hline S/N & Set & Year & E.R.H. (hours) & T.D.T. (hours) & T.H.R. (hours) & T.N.S. (hours) & P.G. (MWH) \\
\hline 1 & 2 & 1995 & 8760 & 4,408 & 13,042 & 1066 & $11,094.6$ \\
2 & 2 & 1996 & 8760 & 2,167 & 21,560 & 1483 & $24,275.0$ \\
3 & 2 & 1997 & 8760 & 2,051 & 28,408 & 1658 & $31,964.0$ \\
4 & 2 & 1998 & 8760 & 2,760 & 36,438 & 2234 & $57,215.9$ \\
5 & 2 & 1999 & 8760 & - & 38,711 & 2437 & $68,016.5$ \\
\hline \multicolumn{7}{r}{} & \multicolumn{7}{c}{ May 1999 - January 2000 (Overhaul of both sets) } \\
\hline 6 & 1 & 1999 & 8760 & - & 37,656 & 3420 & 66,360 \\
7 & 1 & 2000 & 8760 & - & 46,951 & 3565 & $98,504.2$ \\
\hline
\end{tabular}

E.R.H. Expected running hours

T.N.S. Total number of starts
T.D.T. Total down time

P.G. Power generated
T.H.R. Total hours run

M.W.H. Mega Watt Hour

\subsection{Data Analysis}

In processing the data, mean time between failure $(M T B F)$, mean time to repair (MTTR), availability $(A)$ and reliability $(R(t))$ were obtained. Reliability deals with reducing the frequency of failure over a time interval and is a measure of probability of failure-free operations during a given interval i.e. it is a measure of success for failure-free operations. It is expressed as

$$
R(t)=e^{\left(\frac{-t}{M T B F}\right)}=e^{-\lambda t}
$$

where $\lambda=$ constant failure rate

$M T B F=$ mean time between failure $=\frac{1}{\lambda}$

$\mathrm{t}=$ Time of failure free operation

$M T B F$ is a measure of how long, on average, equipment will perform as specified before an unplanned failure will occur. It can also be expressed as

$$
\text { MTBF } \frac{\text { Total operating time }}{\text { Number of failures }}
$$

Mean time to repair is expressed as

$$
\begin{aligned}
M T T R & =\frac{\text { Total outage time }}{\text { Number of failure }} \\
\text { Repair rate }(\mu) & =\frac{\text { Number of repairs }}{\text { Unit time }}=\frac{1}{M T T R}
\end{aligned}
$$

When these two factors are known for any system or component then availability ' $A$ ' is expressed as

$$
A=\frac{\mu}{\lambda+\mu}
$$

$$
A=\frac{\text { Uptime }}{\text { Total time considered }}=\frac{M T B F}{M T B F+M T T R}
$$

Availability (A) is a measure of the percentage of time that an equipment is capable of producing its end product at some specified acceptable level. In the case of a turbine in a power plant, availability is a measure of the fraction of time that it is generating the nominal power output.

\section{RESULTS AND DISCUSSION}

Table 4 presents reliability indices that considered all forms of failure in the gas turbine power plant from 1995 to 2001.

The result shows a very low value of reliability and availability of $10 \%$ and $70.5 \%$ respectively. These low values are indications of several failures and long downtimes, most of the failures were related to excessive vibration on the bearings.

Hence, the chance of successful failure free operation for a period of seven years is $10 \%$, which is below

\begin{tabular}{|c|c|c|c|c|c|c|c|c|c|c|}
\hline $\mathrm{S} / \mathrm{N}$ & Year & T.O.H & $\mathrm{T}_{2} . \mathrm{O} . \mathrm{H}$ & N.O.F & MTBF & MTTR & $\lambda$ & $\mu$ & $A(\%)$ & $\mathrm{R}(\mathrm{t}) \%$ \\
\hline 1 & 1995 & 6352 & 2408 & 3 & 2117 & 802.6 & $4.7 \times 10^{-4}$ & $1.25 \times 10^{-4}$ & 73 & 5.0 \\
\hline 2 & 1996 & 8518 & 242 & 2 & 4259 & 121 & $2.35 \times 10^{-4}$ & $8.26 \times 10^{-4}$ & 97 & 14.0 \\
\hline 3 & 1997 & 6843 & 1917 & 2 & 3422 & 958.5 & $2.92 \times 10^{-4}$ & $1.04 \times 10^{-4}$ & 78 & 13.6 \\
\hline 4 & 1998 & 8032 & 725 & 2 & 4018 & 362.5 & $2.49 \times 10^{-4}$ & $2.75 \times 10^{-4}$ & 92 & 13.5 \\
\hline 5 & 1999 & 2274 & 6486 & 2 & 1137 & 3243 & $8.8 \times 10^{-4}$ & $3.08 \times 10^{-4}$ & 26 & 13.5 \\
\hline 6 & 2000 & 3006 & 5754 & 2 & 1505 & 2877 & $6.6 \times 10^{-4}$ & $3.46 \times 10^{-4}$ & 34 & 13.7 \\
\hline 7 & 2001 & 8240 & 520 & 3 & 2747 & 173.3 & $3.64 \times 10^{-4}$ & $5.78 \times 10^{-4}$ & 94 & 4.0 \\
\hline
\end{tabular}
standard. Table 4 also reveals that availability is higher from 1995 to 1998 with total operating hours from $6352,8518,6543,8032$, while in 1999 only 2274 hours out of 8760 expected hours of operation was available.

Table 4: Reliability indices

Average values

\begin{tabular}{llllllclc}
\hline T.O.H & $\mathrm{T}_{2.0 . H}$ & N.O.F & MTBF & MTTR & $\lambda$ & $\mu$ & $\mathrm{A}(\%)$ & $\mathrm{R}(\mathrm{t}) \%$ \\
\hline 6181.1 & 2578.9 & 2.29 & 2699.1 & 1126.3 & $3.70 \times 10^{-4}$ & $8.88 \times 10^{-4}$ & 70.5 & 10 \\
\hline T.O.H & Total Operating Hour & $\mathrm{T}_{2}$.O.H & Total Outage Hour & \multicolumn{2}{l}{ N.O.F. } & Number of Failure
\end{tabular}


In the first five years of consideration there was no serious outage, it was only in 1999 that the station experienced a major bearing failure which lasted for six months before replacement. A high reliability can only be achieved if no failure occurs in an upward of five years of operation. Furthermore, most of the problems in the station can be traced to maintenance delay, overload of feeders and interruption of gas supply.

\section{CONCLUSION}

Reliability study of Kolo Creek Power Station revealed very low value indicating several failures and long downtime i.e low performance standard. Maintenance problem at the Kolo Creek Gas Turbine Station is very evident in the loss of production; there is a sharp decrease in the power output generated from the station arising from the low level of planned maintenance. Most of the practical problems identified as causes of the low values of the availability and reliability are not age related to the components of the plant but could be traceable to maintenance culture. By assessing the condition and performance of rotating equipment and establishing clearly defined operational procedures, plant equipment runs at its best efficiency point (BEP) and contributing to overall efficiency of operations; reduce downtime and improve reliability; by ensuring proper PM/PDM practices are in place, plant equipment availability is improved, which in turn leads to increased productivity and profit; by improving equipment reliability, maintenance costs decrease and equipment life span increases, which results in a reduced total cost of operation. Therefore a strict adherence to maintenance tradition is required to improve the reliability of the plant.

\section{RECOMMENDATION}

In an electric power station a high value of reliability and availability is required for optimum performance. Therefore engineering solution in terms of preventing and predicting failure should be employed to ensure continuous operation because failure is not acceptableit cost money in economic terms.

\section{REFERENCES}

[1] Anirban, B. and Samy, M. " Reliability assessment using probabilistic support vector machines". International Journal. of Reliability and Safety, 7 (2), $156-173,2013$.

[2] Barabady, J. and Kumar, U. Availability Allocation through Importance Measures, International Journal of Quality and Reliability Management, 24 (6), 643 - 657, 2007.

[3] Fernando, J., Guevara, C. and Gilberto, F. M. "Availability Analysis of Gas Turbines Used in Power Plants". International Journal. of Thermodynamics, 12 (1), 28-37, 2009.

[4] Gupta, S.A. and Tewari, C.P. " Simulation Model for Coal Crushing System of a Typical Thermal Power Plant". International Journal of Engineering and Technology, 1 (2), 156 - 163, 2006.

[5] Manwinder, K., Arvind, K., Satvinder, S. B. and Akepati, S. R. "The Use of Corrective Maintenance Data for Performance Analysis of Preventively Maintained Textile Industry". Journal of Reliability and Statistical Studies 6 (2), 151-163, 2013.

[6] Monika, M. and Mangey, R. " Reliability Analysis of a Two Unit Cold Standby System using Markov Process". Journal of Reliability and Statistical Studies 6 (2), 65-80, 2013.

[7] Phaneendra, K. C. and Agrawal, V. P. "Mechatronic System Reliability Modelling and Analysis: A Graph Theoretic Approach". International Journal of Reliability and Safety, 7 (2), $128-155,2013$.

[8] Valdma, M., Keel, M. Tammoja, H., and Kilk, K. “ Reliability of Electric Power Generation in Power Systems with Thermal and Wind Plants". International Journal of Quality and Reliability Management, 24(2), 197- 208, 2007.

[9] Wang, P., Billinton, R. and Goel, L. "Unreliability Cost Assessment of an Electric Power System using Reliability Network Equivalent Approaches". IEEE Transactions on Power System, 17 (3), 549 - 556, 2002. 